\title{
Synthesis and Characterization of Nano-
} $\mathrm{SiO}_{2} @$ @octadecylbisimidazoline Quaternary

\section{Ammonium Salt Using as Acidizing Corrosion Inhibitor}

\section{Yunfeng Liu ( $\sim$ lyf6280168@126.com )}

Research Institute of Natural Gas Technology, Southwest Oil and Gas Field Company of PetroChina Xingde Zhang

Research Institute of Natural Gas Technology, Southwest Oil and Gas Field Company of PetroChina Zhengsong Qiu

China University of Petroleum (East China)

Lili Chen

Southwest Oil and Gas Field Company of PetroChina

\section{Research Article}

Keywords: acidizingcorrosion inhibitor, nano-SiO2, imidazoline, quaternary ammonium salt, isothermal adsorption, quantum chemistry

Posted Date: September 23rd, 2021

DOl: https://doi.org/10.21203/rs.3.rs-898284/v1

License: (c) (1) This work is licensed under a Creative Commons Attribution 4.0 International License. Read Full License 


\section{Abstract}

Aiming at the current situation that the existing acidizing corrosion inhibitors are difficult to apply to high temperature, high concentration acid, and other complex conditions. This paper uses nano- $\mathrm{SiO}_{2}$ as the

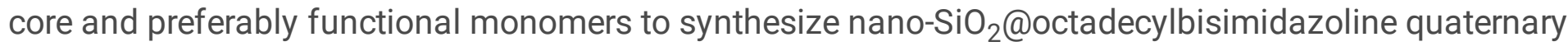
ammonium salt. Analytical methods such as nuclear magnetic resonance, infrared, SEM were used for characterization. The corrosion inhibition performance of the N80 steel sheet by nano$\mathrm{SiO}_{2} @$ octadecylbisimidazoline quaternary ammonium salt in $20 \%$ concentrated hydrochloric acid was studied using the high-temperature corrosion testing machine and adsorption isotherm model. Combined with quantum chemistry calculations to explore its mechanism of action. The results show that nano$\mathrm{SiO}_{2} @$ @octadecylbisimidazoline quaternary ammonium salt has good high-temperature resistance. When the temperature is $180^{\circ} \mathrm{C}$ and the dosage of nano- $\mathrm{SiO}_{2} @$ @octadecylbisimidazoline quaternary ammonium salt is $4 \%$, the corrosion inhibition rate is $61.42 \mathrm{~g} \cdot \mathrm{m}^{-2} \cdot \mathrm{h}^{-1}$. Studies have shown that the adsorption of nano-SiO ${ }_{2} @$ octadecylbisimidazoline quaternary ammonium salt on the surface of the N80 steel sheet follows the Langmuir isotherm adsorption model, which is spontaneous chemical adsorption.

\section{Introduction}

With the development of drilling engineering, the number of deep wells and ultra-deep wells has increased, and the bottom hole environment is gradually becoming more complicated, which puts forward higher requirements for the production of stimulation techniques such as acid fracturing [1-5]. In the oilfield development process, the pickling liquid can effectively increase the output of crude oil, but its corrosion of tubing and other equipment also brings additional operating costs [6-7]. At present, adding acidizing corrosion inhibitor is the most commonly used method of anti-corrosion [8-10], but it has been studied more in low-temperature and low-concentration acid solutions, and less research in hightemperature and high-concentration acid solutions [11]. Therefore, acidizing corrosion inhibitors with high-temperature resistance and high concentration acid resistance have become a problem that needs to be solved urgently.

There are three main methods of anti-corrosion. Firstly, the corrosion can be controlled from the source, that is the development of high-corrosion-resistant metals or the addition of corrosion-resistant elements [12-13]. Secondly, a layer of anti-corrosion paint can be applied to the metal surface to isolate the metal from the corrosive environment [14-15]. In the third aspect, acidizing corrosion inhibitors can be added [16]. This method is the easiest to operate, cheapest and effective, but it also has problems such as high toxicity and difficult degradation [17-18]. Based on this, the development of low-toxic and easily degradable acidizing corrosion inhibitors is particularly important [19]. Imidazoline acidizing corrosion inhibitors are a commonly used type in oilfields. They can form a film structure on the metal surface through chemical adsorption to prevent direct contact between acid and metal. At the same time, imidazoline acidizing corrosion inhibitors have the advantages of low toxicity, high efficiency, and 
excellent thermal stability [20-22]. Therefore, imidazoline acidizing corrosion inhibitors are widely used in oil and gas field development projects.

The application of nanomaterials has improved efficiency for oil and gas field development projects [2324], especially the treatment agent with a "core-shell" structure obtained by combining inorganic and organic materials. This can be explained by the nanomaterials provide a rigid skeleton structure for the polymer. On the one hand, it can improve the temperature resistance of the polymer. On the other hand, it can enter the fracturing channel and play the role of supporting the channel. Therefore, the research and development of acidizing corrosion inhibitors with the framework of inorganic nanomaterials have great significance.

\section{Materials And Methods}

\subsection{Materials}

Azelaic acid, analytical grade, Shanghai Macleans Biochemical Technology Co., Ltd. N-(2-hydroxypropyl) ethylenediamine, analytical grade, Jiangsu Aikang Biomedical R\&D Co., Ltd. Xylene, analytical grade, Shanghai Macleans Biochemical Technology Co., Ltd. Acetone, absolute ethanol, $\mathrm{Al}_{2} \mathrm{O}_{3}$, analytically pure, Shanghai Aladdin Biochemical Technology Co., Ltd. 4-methoxy-3-methyl benzyl chloride, chemically pure, Beijing Hanlongda Technology Development Co., Ltd. 4 -Methoxy-3-methyl-1-chloromethane-cyclohexane, industrial grade, Weifang Qianjin Fine Chemical Co., Ltd.

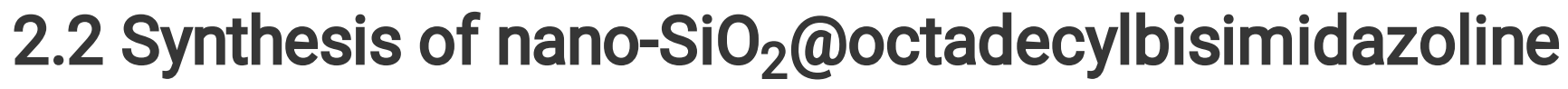 quaternary ammonium salt}

(1) Surface coating of nano-SiO ${ }_{2}$ microspheres

Disperse $0.05 \mathrm{~mol}$ nano- $\mathrm{SiO}_{2}$ microspheres in $200 \mathrm{~mL}$ deionized water solution, slowly add $0.2 \mathrm{~mol}$ azelaic acid dropwise, stir at $300 \mathrm{rpm}$ at $20^{\circ} \mathrm{C}$ for $3 \mathrm{~h}$, filter and freeze-dry to obtain nano-SiO ${ }_{2}$ microspheres coated with azelaic acid.

(2) Synthesis of nano-SiO ${ }_{2} @$ bisimidazoline intermediate

Put the product obtained in step (1) into a $500 \mathrm{~mL}$ three-necked flask equipped with an electric stirrer, a water separator, and a spherical condenser, and then slowly add $10 \mathrm{~mL}$ of xylene at $5 \mathrm{~mL} / \mathrm{min}$, and add $0.01 \mathrm{~mol}$ of the catalyst $\mathrm{Al}_{2} \mathrm{O}_{3}$, Stir for $20 \mathrm{~min}$, then slowly add $0.5 \mathrm{~mol}$ of $\mathrm{N}$-(2-hydroxypropyl) ethylenediamine into the system with a constant pressure drop funnel, and reflux at $170^{\circ} \mathrm{C}$ for $6 \mathrm{~h}$, then react at $190^{\circ} \mathrm{C}$ for $10 \mathrm{~h}$. Use a rotary evaporator to evaporate and remove toluene at $150^{\circ} \mathrm{C}$ to obtain a bisimidazoline quaternary ammonium salt intermediate (Fig. 1).

(3) Quaternization reaction 
Disperse $0.2 \mathrm{~mol}$ of bisimidazoline quaternary ammonium salt intermediate in $250 \mathrm{~mL}$ of absolute ethanol to fully dissolve it, and add $0.5 \mathrm{~mol}$ of 4-methoxy-3-methyl-benzyl chloride at $40-50{ }^{\circ} \mathrm{C}$ for quaternization. After reacting for $2-4 \mathrm{~h}$, the absolute ethanol is distilled out under reduced pressure, and then recrystallized three times with a mixed solution of ethanol and acetone in an ice-water bath, and dried in a vacuum drying oven to obtain the final product nano-SiO ${ }_{2} @$ octadecyl Imidazoline quaternary ammonium salt ( $\left.\mathrm{SiO}_{2} @ \mathrm{OBQA}\right)$ (Fig. 2).

\subsection{Characterization of physical and chemical properties}

The nano-SiO ${ }_{2} @ O B Q A$ was analyzed by infrared spectroscopy (resolution $4 \mathrm{~cm}^{-1}$, wavenumber range $4000-400 \mathrm{~cm}^{-1}$, scanning number 32) using American Thermo Fisher Nicolet IS5 FT-IR spectrometer. ${ }^{1} \mathrm{H}$ NMR analysis was performed on nano-SiO ${ }_{2} @ O B Q A$ with a German Bruker AVANCE III 500MHz nuclear magnetic resonance spectrometer (resolution $\leq 0.2 \mathrm{~Hz}$, sensitivity $390: 1(5 \mathrm{mm0} 0.1 \% \mathrm{~EB})$ ). The thermal stability of nano-SiO ${ }_{2} @ O B Q A$ was evaluated using the TG/DTA7300 thermogravimetric dual analyzer of Japan HITACHI company (the test temperature range is $20-600^{\circ} \mathrm{C}$, the heating rate is $10^{\circ} \mathrm{C} / \mathrm{min}$, and the test gas atmosphere is $\mathrm{N}_{2}$ ). The microstructure of nano- $\mathrm{SiO}_{2} @ O B Q A$ was characterized by the $\mathrm{S}-4800$ SEM analyzer of Hitachi.

\subsection{Evaluation of corrosion inhibition performance}

Taking the N80 steel sheet as the corrosion test piece, the influence of temperature and nano-SiO ${ }_{2} @ 0 B Q A$ concentration on corrosion inhibition performance was explored. The experiment uses two sets of parallel experiments to eliminate accidental errors and calculates the corrosion inhibition rate according to formula (1).

$$
\eta=\frac{v_{0}-V}{v_{0}} \times 100 \%
$$

1

Among them, $\eta$-corrosion inhibition rate,\%. $v$-corrosion rate of steel sheet after adding acidizing corrosion inhibitor, $\mathrm{g} \cdot \mathrm{m}^{-2} \cdot \mathrm{h}^{-1}, v_{0}$-corrosion rate of steel sheet in acid, $\mathrm{g} \cdot \mathrm{m}^{-2} \cdot \mathrm{h}^{-1}$.

\subsection{Quantum Chemistry Research}

Using the Chem3D Ultra program and the Huckel molecular orbital theory, the molecular structure optimization and quantum chemical calculations of the nano-SiO ${ }_{2} @ O B Q A$ molecule are carried out.

\section{Results And Discussion}

\subsection{Molecular structure characterization}

\subsubsection{The analysis of FT-IR}


It can be seen from Fig. 3 that $3401.13 \mathrm{~cm}^{-1}$ is the stretching vibration peak of $-\mathrm{OH}, 2924.04 \mathrm{~cm}^{-1}$ and $2853.65 \mathrm{~cm}^{-1}$ are the stretching vibration peaks of $-\mathrm{CH}_{3}$ and $-\mathrm{CH}_{2}$, and $1614.13 \mathrm{~cm}^{-1}$ is the stretching vibration of $\mathrm{C}=\mathrm{N}$. Peaks, $1461 \mathrm{~cm}^{-1}$ and $1374.62 \mathrm{~cm}^{-1}$ are the stretching vibration peaks of $\mathrm{C}-\mathrm{H}$, $1213.00 \mathrm{~cm}^{-1}$ and $1086 \mathrm{~cm}^{-1}$ are the stretching vibration peaks of C-N, $1010.04 \mathrm{~cm}^{-1}$ are the stretching vibration peaks of $\mathrm{C}-0,879.86 \mathrm{~cm}^{-1}$ and $754.03 \mathrm{~cm}^{-1}$ is the characteristic peak of the mono-substituted benzene ring. Therefore, it can be explained that nano-SiO ${ }_{2} @ O B Q A$ was successfully synthesized.

\subsubsection{The analysis of ${ }^{1} \mathrm{H}-\mathrm{NMR}$}

It can be seen from Fig. 4 that nano-SiO ${ }_{2} @ O B Q A$ mainly has 9 kinds of absorption peaks, including 9 kinds of hydrogen atoms. $0-2 \mathrm{ppm}$ is alkane structure, 2-4 ppm is $\mathrm{CH}_{-} \mathrm{NH}_{2}$, hydroxyl structure, and 7.28 $\mathrm{ppm}$ is benzene ring structure. Among them, the absorption peak area with a chemical shift of $1.24 \mathrm{ppm}$ is larger, indicating that the carbon chain in the alkane structure is longer, which can improve the temperature resistance of the imidazoline quaternary ammonium salt to a certain extent. The chemical shift of 2-4 ppm shows that an imidazoline ring is formed. At the same time, the addition ratio of azelaic acid and $\mathrm{N}$-(2-hydroxypropyl)-ethylenediamine is 2:5, ensuring that azelaic acid can be combined with $\mathrm{N}$ (2-Hydroxypropyl)-ethylenediamine fully reacted to form a bisimidazole ring, which also shows that the imidazoline quaternary ammonium salt was successfully synthesized. The absorption peak with a chemical shift of $7.28 \mathrm{ppm}$ indicates the presence of a benzene ring in the structure, which further improves the temperature resistance of the bisimidazoline quaternary ammonium salt.

\subsubsection{The analysis of Thermogravimetric}

It can be seen from Fig. 5 that the first mass loss of about $20 \%$ occurs in the range of room temperature to $100^{\circ} \mathrm{C}$, which is mainly caused by the gradual evaporation of adsorbed water and bound water in the sample. At this time, the large mass loss rate is mainly due to the bisimidazoline intermediate produced by the reaction of azelaic acid and $\mathrm{N}$-(2-hydroxypropyl)-ethylenediamine with benzyl chloride. Among them, the molar ratio of azelaic acid to $\mathrm{N}$-(2-hydroxypropyl)-ethylenediamine is $2: 5$, and excess $\mathrm{N}-(2-$ hydroxypropyl)-ethylenediamine can ensure that two steps of dehydration will occur and the final formation of bisimidazoline. When the temperature is $100-300^{\circ} \mathrm{C}$, the methoxy group and the methyl group on the molecular branch of the emulsifier will be broken, and the second mass-loss rate is about $8.0 \%$. When the temperature is $300-500^{\circ} \mathrm{C}$, the mass-loss rate is about $50 \%$. The mass-loss is mainly caused by the rupture of the imidazoline ring and main chain in the molecular structure of the emulsifier. The maximum mass loss occurs at $330^{\circ} \mathrm{C}$. The results show that the bisimidazoline quaternary ammonium salt emulsifier nano-SiO ${ }_{2} @ O B Q A$ has better thermal stability.

\subsubsection{Microstructure characterization}

The result is shown in Fig. 6. The particle size of nano-SiO ${ }_{2} @ O B Q A$ is $2-5 \mu \mathrm{m}$, the particle size distribution is uniform, the sphericity is excellent, and there is adhesion between a small number of particles as shown in Fig. 6(b). Which may be due to the synthesis process of bisimidazoline, the $\mathrm{SiO}_{2}$ 
microspheres adhere to each other by adsorption. This can indicate that the octadecyl bisimidazoline quaternary ammonium salt successfully coated $\mathrm{SiO}_{2}$.

\subsection{Quantum Chemistry Research}

Chooto believes that during the reaction of molecules, molecular orbitals interact, and frontal orbitals have priority [25]. For acidizing corrosion inhibitors, it is generally believed that quantization parameters such as the highest occupied orbital energy EHOMO and the lowest occupied orbital energy ELUMO can characterize the interaction between acidizing corrosion inhibitor molecules and metal atoms. Among them, the HOMO orbital represents the ability to provide monads, the LUMO orbital represents the ability to accept electrons, and the difference between the energy of the HOMO orbital and the LUMO orbital is the energy gap, which is used to characterize the difficulty of chemical reactions [26].

Huckel analysis orbital theory is used to optimize the molecular structure and quantum chemical calculations of nano-SiO ${ }_{2} @ O B Q A$. As shown in Fig. 7, the imidazoline and the vicinity of the benzene ring on the right side of the acidizing corrosion inhibitor have a higher ability to donate electrons, and the vicinity of the benzene ring on the left side has a higher ability to accept electrons, indicating that the acidizing corrosion inhibitor has the ability to acquire and lose electrons, and form chemical adsorption with atoms on the metal surface, reducing the corrosion of the metal by the acid solution. At the same time, the energy range $(\Delta \mathrm{E})$ is $1.087 \mathrm{eV}$, indicating that the reaction is easier. As shown in Table 1, the value of $\left(E_{\mathrm{LUMO}}\right.$ SiO2@OBQA $\left.-\mathrm{E}_{\mathrm{HOMO}}, \mathrm{Fe}\right)$ is greater than the value of $\left(\mathrm{E}_{\mathrm{LUMO}}, \mathrm{Fe}^{-} \mathrm{E}_{\mathrm{HOMO}}\right.$, SiO2@OBQA $)$, and the difference is greater than $3 \mathrm{eV}$, indicating that the acidizing corrosion inhibitor nano-SiO ${ }_{2} @ O B Q A$ molecule accepts electrons to interact with $\mathrm{Fe}$ is smaller than the tendency to donate electrons to interact with $\mathrm{Fe}$ [27].

\section{Table 1}

Frontier orbital energies of nano-SiO 2 @OBQA

\begin{tabular}{|c|c|c|c|c|c|}
\hline Molecular & $\mathrm{E}_{\text {момо }} / \mathrm{eV}$ & $E_{\text {LUMO }} / \mathrm{eV}$ & $\begin{array}{l}\mathrm{E}_{\mathrm{LUMO}, \mathrm{SiO}} @ \mathrm{OBQA}^{-} \\
\mathrm{E}_{\mathrm{HOMO}, \mathrm{Fe}} / \mathrm{eV}\end{array}$ & $\begin{array}{l}E_{\text {LUMO, } \mathrm{Fe}^{-}} \\
\mathrm{E}_{\text {HOMOロSiO2@OBQA }} / \mathrm{eV}\end{array}$ & $\Delta \mathrm{E} / \mathrm{eV}$ \\
\hline $\mathrm{SiO}_{2} @ O B Q A$ & -0.631 & 0.456 & 8.266 & 0.381 & 1.087 \\
\hline $\mathrm{Fe}$ & -7.81 & -0.25 & - & - & - \\
\hline
\end{tabular}

\subsection{Evaluation of corrosion inhibition performance}

Different mass fractions of nano-SiO ${ }_{2} @ O B Q A$ were added to $400 \mathrm{~mL} 20 \%$ hydrochloric acid solution. The corrosion of the $\mathrm{N} 80$ steel sheet was tested at different temperatures within $4 \mathrm{~h}$, and its adsorption performance was characterized.

The corrosion rate and corrosion inhibition rate are shown in Fig. 8. When the temperature is constant, the corrosion rate decreases as the concentration of nano- $\mathrm{SiO}_{2} @ \mathrm{OBQA}$ increases. This is because nano- 
$\mathrm{SiO}_{2} @ O B Q A$ can adhere to the surface of the N80 steel sheet to form a protective layer to inhibit acid corrosion. As the concentration of nano-SiO ${ }_{2} @ O B Q A$ increases, the area attached to the $\mathrm{N} 80$ steel sheet also increases. When the concentration is constant, the surface coverage reaches the maximum. Behave as the corrosion rate first drops sharply, and then basically remains unchanged. When the concentration of nano-SiO ${ }_{2} @ O B Q A$ is constant, the corrosion rate increases as the temperature increases. This is caused by the thermal movement of molecules. Hoar believes that the increase in temperature helps to increase the absorption rate of inhibitor molecules [25], but the molecular movement of the acid will also increase with the increase in temperature. At the same time, Schmid found that metal surfaces included in organic molecules also undergo corrosion reactions, but the reaction rate is lower than that of bare metal surfaces [28]. Therefore, this can also explain the above-mentioned experimental phenomenon.

\subsection{Adsorption isotherm model}

The isothermal adsorption model of nano-SiO ${ }_{2} @ O B Q A$ was constructed, and the Gibbs free energy $\Delta G^{\circ}$ ads was calculated by the formula to characterize the spontaneity of the adsorption process and the stability of the adsorption layer on the steel surface. It can be seen from Fig. 9 and Table 2 that the size of $R^{2}$ is close to 1 , indicating that the curve fits well and follows the Langmuir isotherm adsorption model. The Gibbs free energy is negative, indicating that the adsorption process between the organic molecules and the steel sheet is spontaneous and stable. Generally, when the value of $\Delta \mathrm{G}^{\circ}$ ads is about $-20 \mathrm{~kJ} \cdot \mathrm{mol}^{-1}$, the steel sheet and the organic molecules interact through electrostatic at this time. When the value of $\Delta G^{\circ}$ ads is around $-40 \mathrm{~kJ} \cdot \mathrm{mol}^{-1}$, the steel sheet and organic molecules are adsorbed by chemical interaction [29-32]. According to the table, the range of $\triangle \mathrm{G}^{\circ}$ ads of nano- $\mathrm{SiO}_{2} @ O B Q A$ is between -28 and $-37 \mathrm{~kJ} \cdot \mathrm{mol}^{-1}$, indicating that the two are mainly through chemical adsorption. As the temperature increases, the Gibbs free energy first decreases and then increases, indicating that the adsorption capacity first increases and then decreases. This can also explain the rapid increase in the corrosion rate when the temperature is greater than $120^{\circ} \mathrm{C}$. Combined with the results of quantum chemistry, it can be considered that the mechanism of action of nano-nano-SiO ${ }_{2} @ O B Q A$ is likely to be due to the $\pi$ electrons of the benzene ring, the unbound electron pairs of oxygen in the methoxy group, the $\mathrm{C}=\mathrm{N}$ double bond on the bisimidazoline ring, and the $\mathrm{N}$ atom with a lone pair of electrons can provide electrons and then covalently with the metal surface.

Table 2

The isotherm fitting parametres 


\begin{tabular}{|lllll|}
\hline $\mathbf{T} / \mathrm{K}$ & Intercept $/\left(\mathrm{mmol} \cdot \mathrm{L}^{-1}\right)$ & $K_{\text {ads }}\left(\mathrm{L} \cdot \mathrm{mmol}^{-1}\right)$ & $\Delta \mathbf{G}^{\circ} \mathrm{ads} /\left(\mathrm{kJ} \cdot \mathrm{mol}^{-1}\right)$ & $R^{2}$ \\
\hline 333.15 & 0.0009 & 1111.1111 & -30.21 & 1 \\
\hline 353.15 & 0.001 & 1000 & -31.71 & 1 \\
\hline 373.15 & 0.0011 & 909.0909 & -33.22 & 1 \\
\hline 393.15 & 0.0013 & 769.2308 & -34.45 & 1 \\
413.15 & 0.0013 & 769.2308 & -36.20 & 1 \\
433.15 & 0.014 & 71.4286 & -29.41 & 0.99 \\
453.15 & 0.0295 & 33.8983 & -27.97 & 0.99 \\
\hline
\end{tabular}

\subsection{Mechanism discussion}

According to the microscopic characterization and performance evaluation, the molecular mechanism of nano-SiO ${ }_{2} @ O B Q A$ mainly includes two aspects: adsorption mechanism and temperature resistance mechanism as shown in Fig. 10. Generally, the temperature resistance of the polymer can be improved by increasing the rigidity of the main chain and the side chain. The nano-SiO ${ }_{2} @ O B Q A$ molecule synthesized has good thermal stability because of the long carbon chain and the benzene ring structure. Meanwhile, the introduction of inorganic nanomaterials will also improve the temperature resistance of molecules to a certain extent [33-34]. Thereby, corrosion inhibition needs to be closely adsorbed with the metal under different well conditions. Generally divided into physical adsorption and chemical adsorption. On the one hand, the nano-SiO ${ }_{2} @ O B Q A$ molecule contains a longer alkyl hydrophobic chain, which greatly enhances the hydrophobicity of the nano-SiO ${ }_{2} @ O B Q A$ molecule, improves the density of the molecular film of the acidizing corrosion inhibitor on the metal surface. On the other hand, the $\pi$ electron of the benzene ring, the unbound electron of the oxygen in the methoxy group, the $\mathrm{C}=\mathrm{N}$ double bond on the bisimidazoline ring, and the $\mathrm{N}$ atom with a lone pair of electrons can provide electrons and then covalently with the metal surface. The combination forms $\pi-d$ coordination bonds that enhance the activation energy of the metal surface and improve the adsorption capacity of the acidizing corrosion inhibitor molecules on the metal surface. Thereby helping to form a dense adsorption film, reducing the direct contact between the corrosive medium and the metal.

In the process of acid fracturing, it is generally necessary to add rigid materials to support the reservoir channels. Nano-SiO ${ }_{2} @ O B Q A$ has a rigid core structure and is insoluble in hydrochloric acid. Therefore, it can be used as a proppant to enter the oil reservoir channel, reduce operating costs, and achieve the goal of reducing costs and increasing efficiency.

\subsection{Innovation point}

At present, there is no report claiming the introduction of inorganic nanomaterials in acidizing corrosion inhibitors. In this paper, the innovative introduction of electrodeless nanomaterials as the "core" structure 
of acidizing corrosion inhibitors. On the one hand, it can improve the molecular structure strength of the acidizing corrosion inhibitor and improve the thermal stability of the polymer molecules. On the other hand, the acidizing corrosion inhibitor molecules are injected into the formation in acid fracturing operations, they can also act as a support channel in the target formation, thereby improving the operating efficiency of acid fracturing.

\section{Conclusions}

The nano-SiO ${ }_{2} @ O B Q A$ can effectively inhibit the corrosion of steel sheets in $20 \% \mathrm{HCl}$. At $180^{\circ} \mathrm{C}$, when the addition of nano- $\mathrm{SiO}_{2} @ \mathrm{OBQA}$ is $4 \%$, the corrosion rate is $61.42 \mathrm{~g} \cdot \mathrm{m}^{-2} \cdot \mathrm{h}^{-1}$, and the corrosion inhibition rate reaches more than 95\%. The nano-SiO ${ }_{2} @ O B Q A$ has excellent corrosion inhibition performance. Studies have shown that the adsorption of nano-SiO ${ }_{2} @ O B Q A$ salt on the surface of the N80 steel sheet follows the Langmuir isotherm adsorption model, which is spontaneous chemical adsorption. At the same time, nano-SiO ${ }_{2} @ O B Q A$ can form stable adsorption with metals.

\section{Declarations}

Funding information: This work was financially supported by the Research Project of Southwest Oil and Gas Field Company of PetroChina named "Popularization and application of $180{ }^{\circ} \mathrm{C}$ high temperature corrosion inhibitor and acid system" (No.20210302-29) and"Research on autogenous acid at $180{ }^{\circ} \mathrm{C}$ and its mechanism" (No.20210302-07). Meanwhile, all the techniques who have contributed this research should be also expressed our most sincere thanks.

Author contributions: Conceptualization-Y.L., Z.Q.; Methodology-Y.L., L.C..; Validation-X.Z., Z.Q.; Investigation-Y.L., X.Z.; Data curation-Y.L., L.C.; Writing-Y.L.; Funding acquisition-X.Z..

\section{Conflicts of interest statement:}

There are no conflicts of interest to declare.

\section{References}

[1] Son AJ, Ballard TM, Loftin RE. Temperature-Stable Polymeric Fluid-Loss Reducer Tolerant to High Electrolyte Contamination[J]. SPE Drilling Engineering, 1987, 2(03): 209-217.

[2] Akpan EU, Enyi GC, Nasr G, et al. Water-based drilling fluids for high-temperature applications and water-sensitive and dispersible shale formations[J]. Journal of Petroleum Science and Engineering, 2019, 175: 1028-1038.

[3] LiuX, Jiang R, Huang W. Experimental study on optimal injection pressure of heavy oil reservoir developed by supercritical $\mathrm{CO}_{2}$ flooding[J]. Fresenius Environmental Bulletin, 2020,29(4), 2555-2561. 
[4]Luo X, Han W, Ren $\mathrm{H}$, et al. Research on high performance temporary plugging drilling fluid for reservoir protection and field trial[J]. Fresenius Environmental Bulletin, 2019, 28(8), 6290-6298.

[5] Soltani A, Head. Reliable level of corrosion inhibitor' sresidual concentration in wet gas-condensate pipelines[C]. Eurocorr 2020 Virtual Conference, 2020.

[6] Shamlooh M, Abdelrady S, Buasali M, et al. Well integrity protection using corrosion inhibitor treatment system for sour gas producers in bahrain field [C]. SPE Middle East Oil and Gas Show and Conference, 2019.

[7] Wylde JJ,Turnern,Austill M, et al. Development, testing and field application of a novel combination foamer-iron sulfide scale inhibitor-corrosion inhibitor in East Texas[C]. SPE International Conference on Oilfield Chemistry, 2017.

[8] Danaee I, Khomami M N. Effect of ethylenediamine on corrosion of AISI 4130 steel alloy in 30\% ethylene glycol solution under static and hydrodynamic condition[J]. Materialwissenschaft Und Werkstofftechnik, 2012, 43(11): 942-949.

[9] Vishwanatham S, Kumar A. Corrosion inhibition of mild steel in binary acid mixture[J]. Corrosion Reviews, 2005, 23(2-3): 181-194.

[10]Ghasemi O, Danaee I, Rashed GR, et al. Inhibition effect of a synthesized N, N'-bis(2hydroxybenzaldehyde)-1, 3-propandiimine on corrosion of mild steel in $\mathrm{HCI}[\mathrm{J}]$. Journal of Central South University, 2013, 20(2): 301-311.

[11] Bentiss F, Lebrini M, Vezin H, et al. Experimental and theoretical study of 3-pyridyl-substituted 1,2,4thiadiazole and 1,3,4-thiadiazole as corrosion inhibitors of mild steel in acidic media [J]. Materials Chemistryand Physics, 2004, 87: 18-23

[12] Jrsa B, Sbia B, Ayga B, et al. Controlling the corrosion resistance of multi-principal element alloys[J]. ScriptaMaterialia, 2020, 188:96-101.

[13] Duarte MJ, Klemm J, Klemm So, et al. Element-Resolved Corrosion Analysis of Stainless-Type GlassForming Steels[J]. Science, 341(6144):372-376.

[14] Qian Y, Li Y, Jungwirth S, et al. The Application of Anti-Corrosion Coating for Preserving the Value of Equipment Asset in Chloride-Laden Environments: A Review[J]. International Journal of Electrochemical Science, 2015, 10:10756-10780.

[15] Cui G, Bi Z, Zhang R, et al. A comprehensive review on graphene-based anti-corrosive coatings[J]. Chemical Engineering Journal, 2019, 373:104-121.

[16] Goyal A, Ganjian E, Pouya HS, et al. Inhibitor efficiency of migratory corrosion inhibitors to reduce corrosion in reinforced concrete exposed to high chloride environment[J]. Construction and Building 
Materials, 2021, 303:124461.

[17] Kobzar YL, Fatyeyeva K. Ionic liquids as green and sustainable steel corrosion inhibitors: Recent developments[J]. Chemical Engineering Journal, 2021, 425:131480.

[18] Baskar R, Lgaz H, Salghi R. Heterocyclic Compounds as Corrosion Inhibitors for Mild Steel: A Review[J]. Chemical Science \& Engineering Research, 2019, 1(1): 32-54.

[19] Saraswat V. Improved corrosion resistant performance of mild steel under acid environment by novel carbon dots as green corrosion inhibitor[J]. Colloids and Surfaces A: Physicochemical and Engineering Aspects, 2021, 627(7): 127172.

[20] Shamsa A, Barmatov E, Hughes TL, et al.Hydrolysis of imidazoline based corrosion inhibitor and effects on inhibition performance of $\mathrm{X} 65$ steel in $\mathrm{CO}_{2}$ saturated brine[J]. Journal of Petroleum Science and Engineering, 2021: 109235.

[21]Shamsa A, Barker R, Hua $Y$, et al. Performance evaluation of an imidazoline corrosion inhibitor in a $\mathrm{CO}_{2}$-saturated environment with emphasis on localised corrosion[J]. Corrosion Science, 2020:108916.

[22] Zhu YQ, Sun QQ, Wang Y, et al. Molecular dynamic simulation and experimental investigation on the synergistic mechanism and synergistic effect of oleic acid imidazoline and I-cysteine corrosion inhibitors [J]. Corrosion Science, 2021, 185: 109414.

[23] Jiang DS, Li XP, Jiang KW, et al. Study on diverting acid conductivity of heterogeneous reservoir in Gaomo area[J].Chemical Engineering of Oil \&Gas, 2021, 50(4): 92-95+113.

[24] Xiong Y, Liu YQ, Mei ZH, et al. Slick water technology of high salinity resistance for shale gas development in Sichuan[J].Chemical Engineering of Oil \&Gas, 2019, 48(3): 62-65+71.

[25] Chooto P, Manaboot S. Electrochemical, spectrochemical and quantum chemical studies on dimedone as corrosion inhibitor for copper in acetonitrile[J]. Journal of Scientific Research \& reports, 2017, 15(2): 1-13.

[26] Mutombo P, Hackerman N. The effect of some organophosphorous compounds on the corrosion behaviour of iron in $6 \mathrm{M} \mathrm{HCl}[\mathrm{J}]$. Anti-corrosion Methods and Materials, 1998,45 (6): 413-418.

[27] Hu SQ, Hu JC, Fan CC, et al. Corrosion inhibition of Q235 steel by a novel imidazoline compound under $\mathrm{H}_{2} \mathrm{~S}$ and $\mathrm{CO}_{2}$ coexistence[J]. Acta Physico-chemicaSinica, 2010, 26(8):2163-2170.

[28] Zhong HY, Kong XZ, Chen S, Grady B, Qiu ZS. (2021) Preparation, characterization and filtration control properties of crosslinked starch nanospheres in water-based drilling fluids[J]. Journal of Molecular Liquids, 325: 115221. 
[29] Cui GD, Zhu L, Zhou, Q, Ren SR, Wang JY. (2021) Geochemical reactions and their effect on $\mathrm{CO}_{2}$ storage efficiency during the whole process of $\mathrm{CO}_{2} \mathrm{EOR}$ and subsequent storage[J]. International Journal of Greenhouse Gas Control, 108: 103335.

[30] Schmid GM, Huang HJ. Spectro-electrochemical studies of the inhibition effect of 4, 7-diphenyl-1, 10phenanthroline on the corrosion of 304 stainless steel[J]. Corrosion Science, 1980, 20(8-9):1041-1057.

[31] Annand RR. Theory of Organic Corrosion Inhibitors Adsorption and Linear Free Energy Relationships[J]. Journal of the Electrochemical Society, 1966, 113(6):633.

[32] Nakonieczny DS, Antonowicz M, Paszenda Z. Surface modification methods of ceramic filler in ceramic-carbon fibre composites for bioengineering applications - A systematic review[J]. Reviews on Advanced Materials Science, 2020, 59(1):586-605.

[33] Khamis E, Bellucci F, Latanision RM, et al. Acid Corrosion Inhibition of Nickel by 2-

(Triphenosphoranylidene) Succinic Anhydride[J]. Corrosion, 1991, 47(9):677-686.

[34] Bentiss F, Traisnel M, Chaibi N, et al. 2,5-Bis(n-methoxyphenyl)-1,3,4-oxadiazoles used as corrosion inhibitors in acidic media: correlation between inhibition efficiency and chemical structure[J]. Corrosion Science, 2002, 44(10):2271-2289.

\section{Figures}

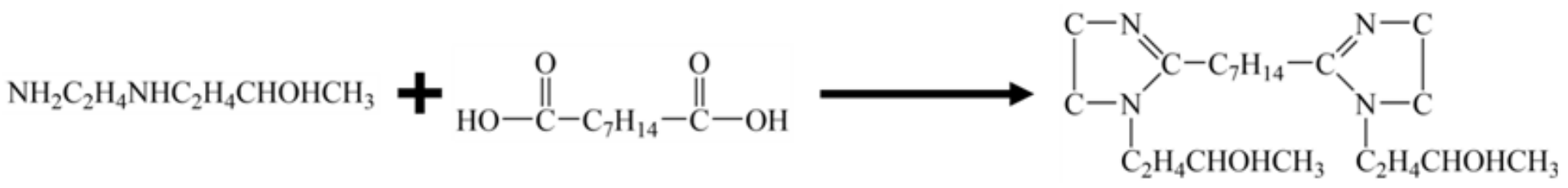

\section{Figure 1}

Synthesis of nano-SiO2@bisimidazoline intermediate

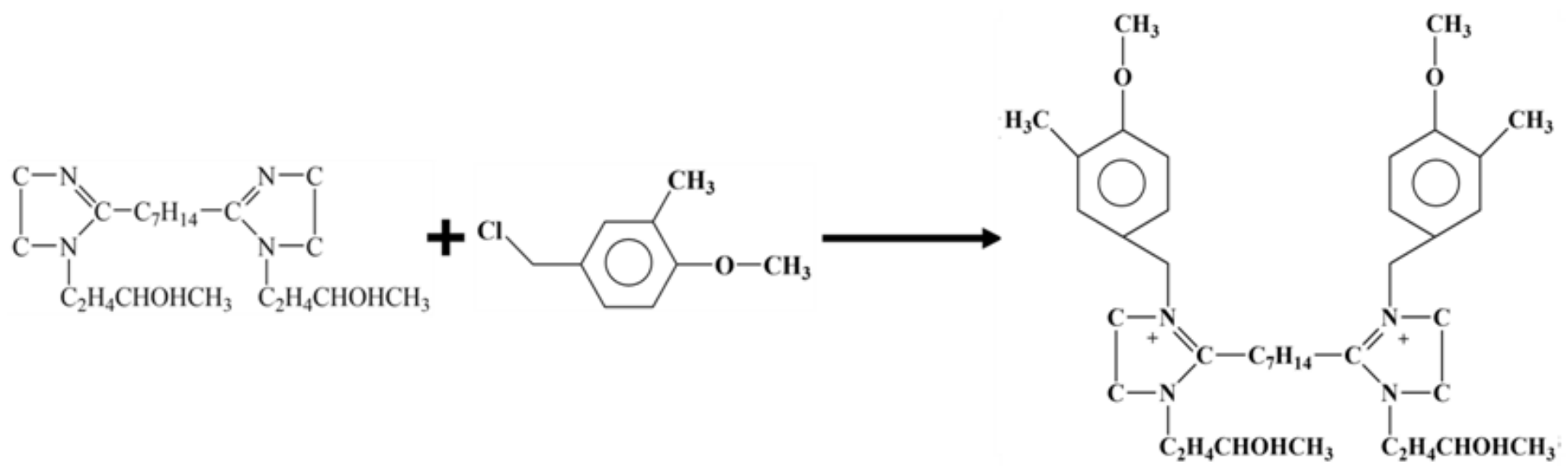


Figure 2

Quaternization reaction

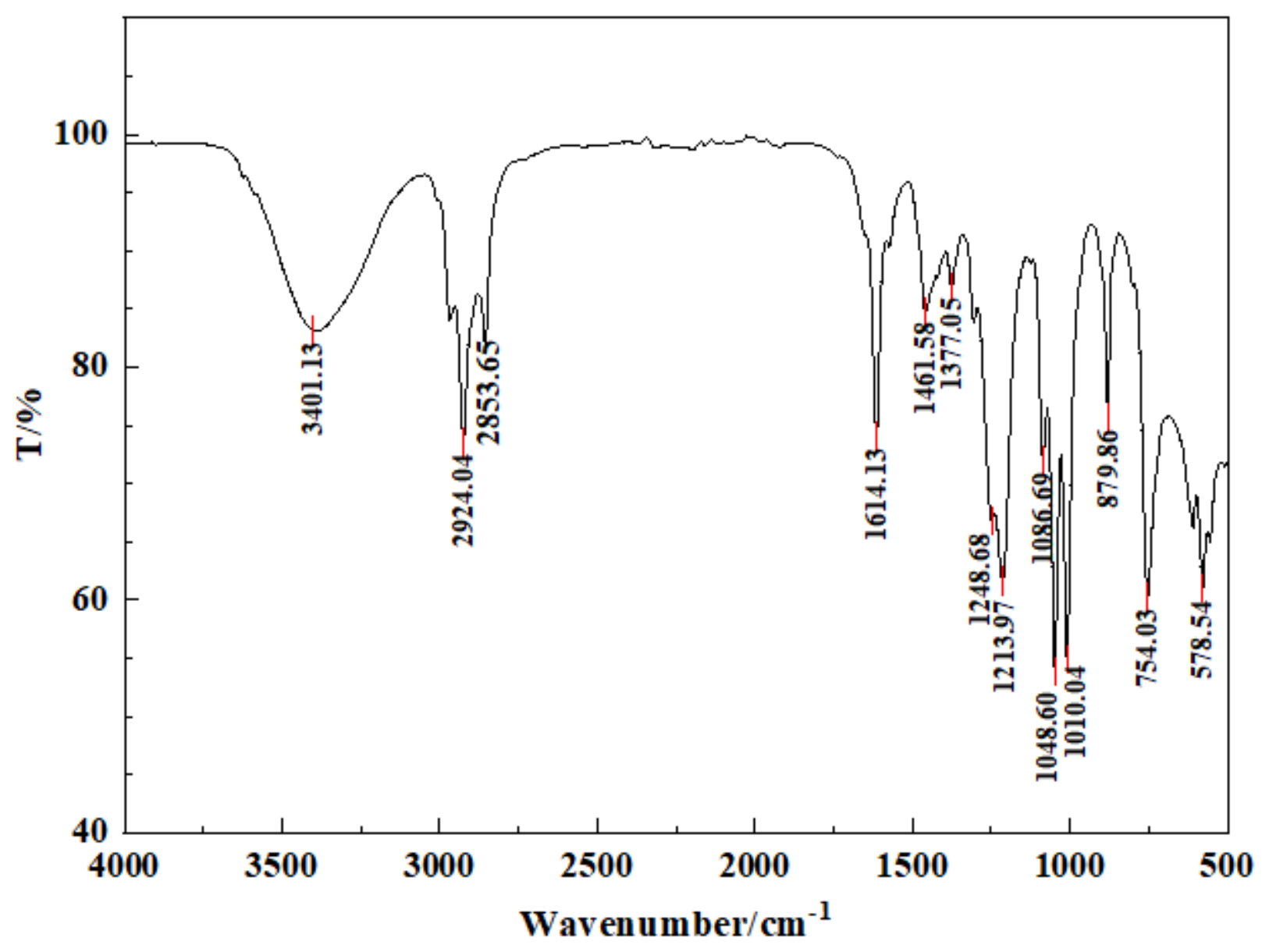

Figure 3

FT-IR analysis of emulsifier nano-SiO2@OBQA 


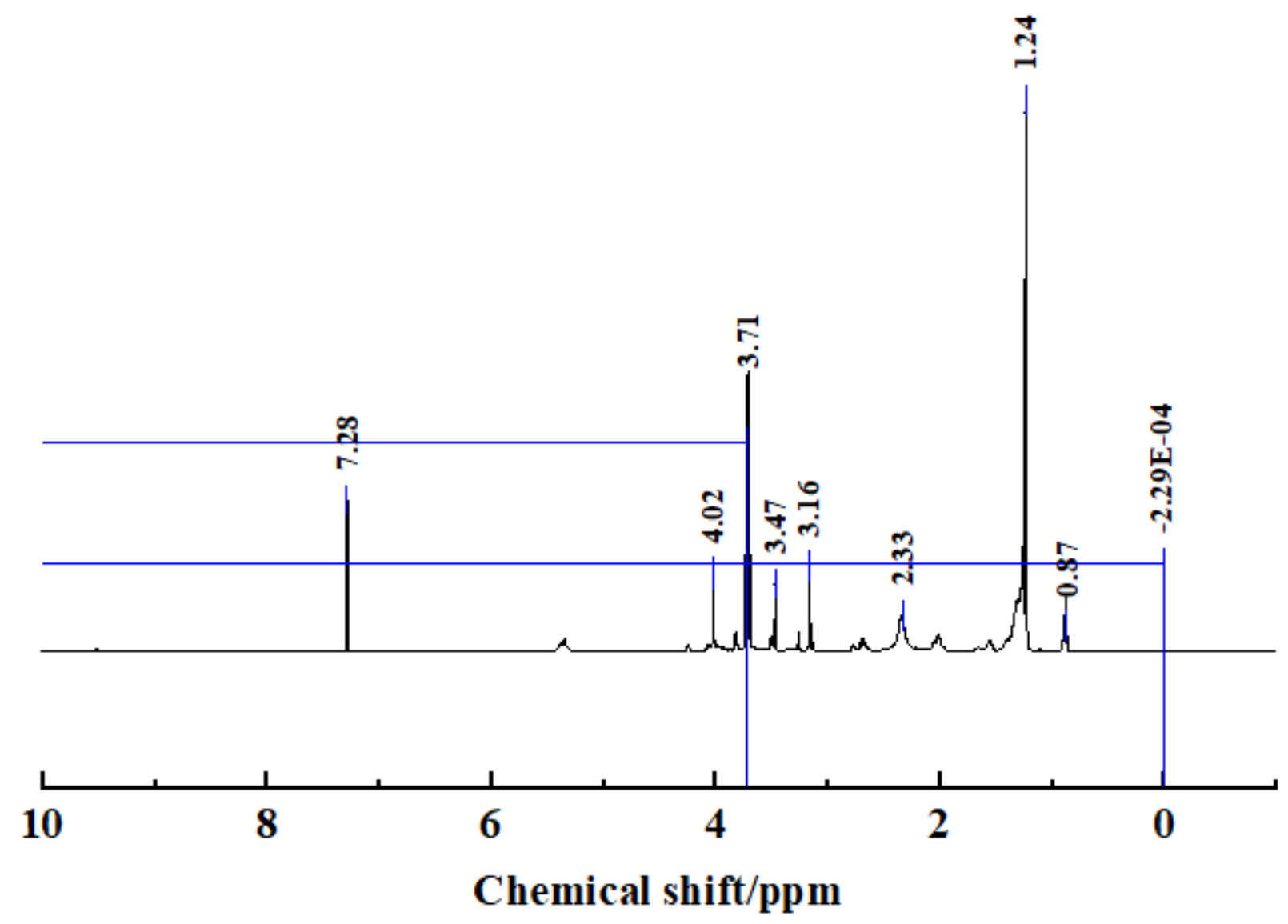

Figure 4

1H-NMR analysis of emulsifier nano-SiO2@OBQA 


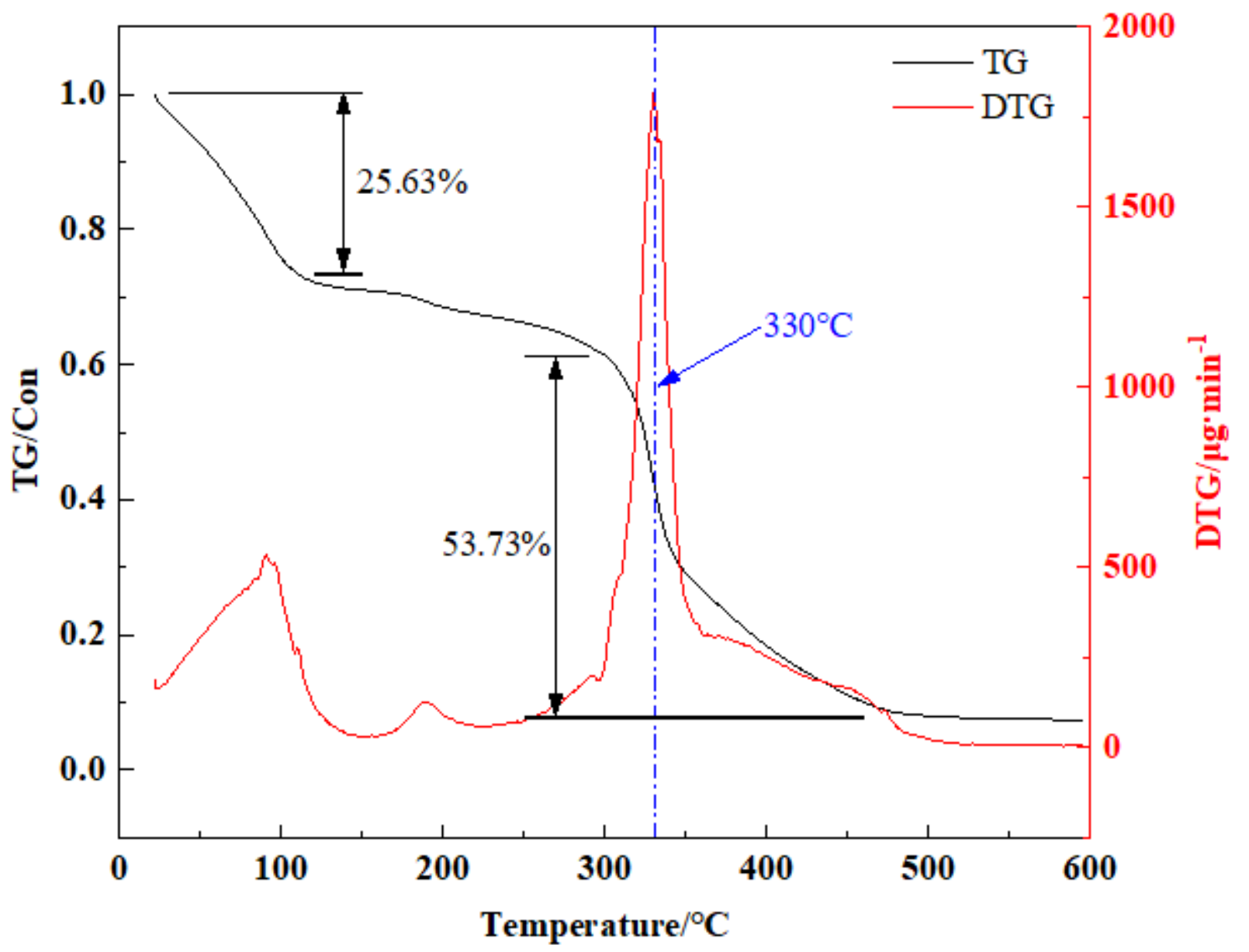

Figure 5

TG and DTG analysis of nano-SiO2@OBQA
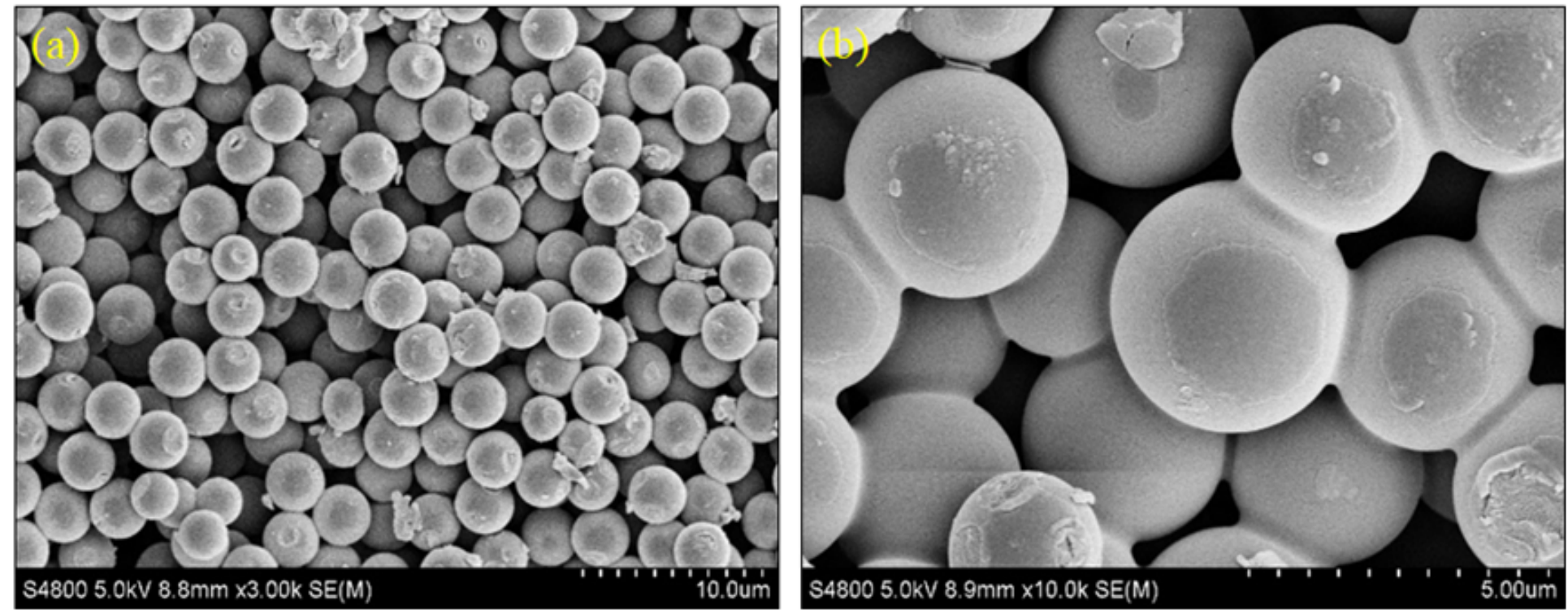

Figure 6

The SEM imageofnano-SiO2@OBQA. 


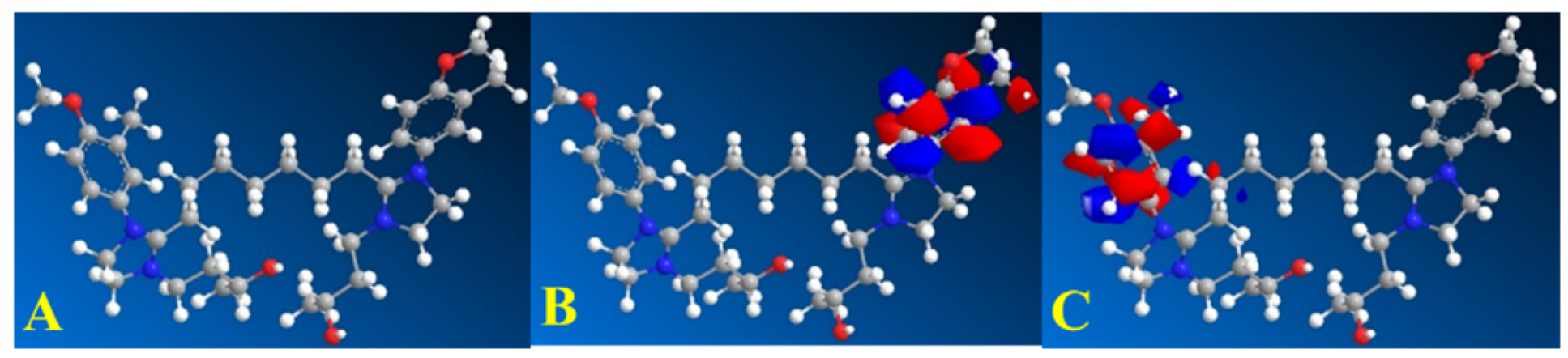

Figure 7

Optimized structure(A), HOMO(B) and LUMO(C) distributions of nano-SiO2@OBQA
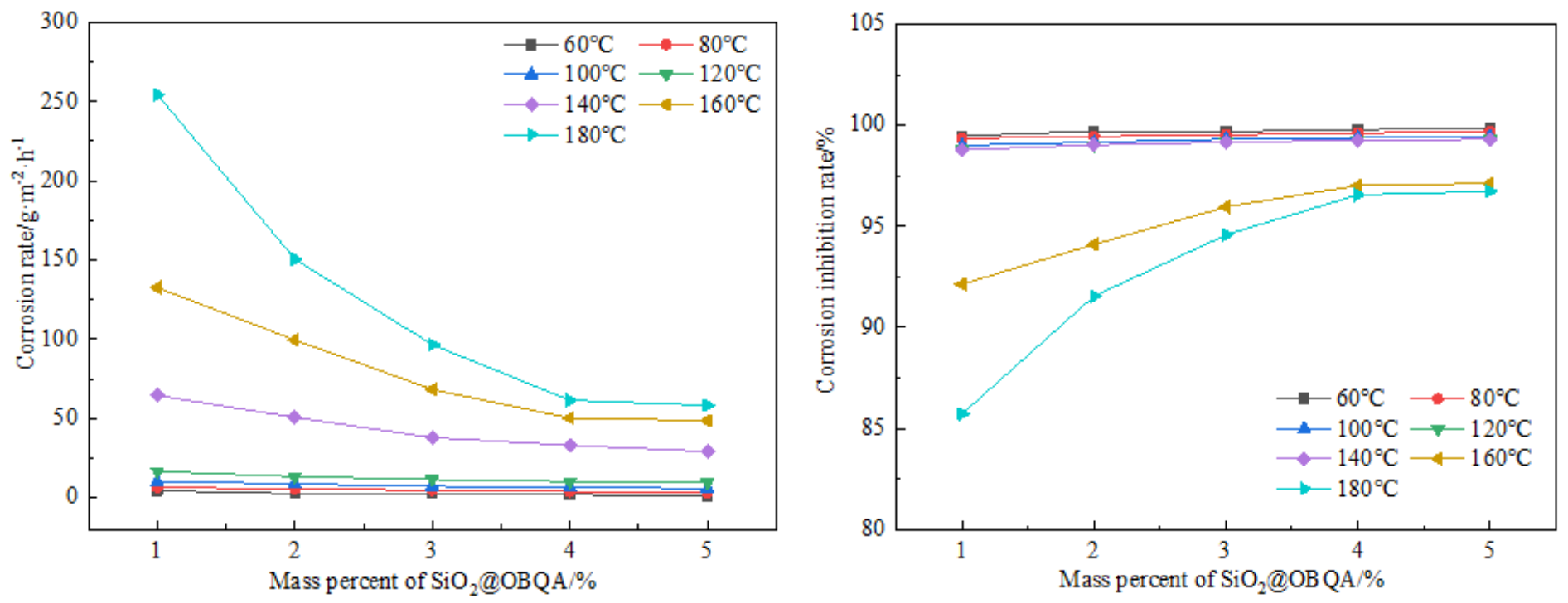

Figure 8

Theinfluence of nano-SiO2@OBQA concentration on corrosion inhibition performance atdifferent temperature 


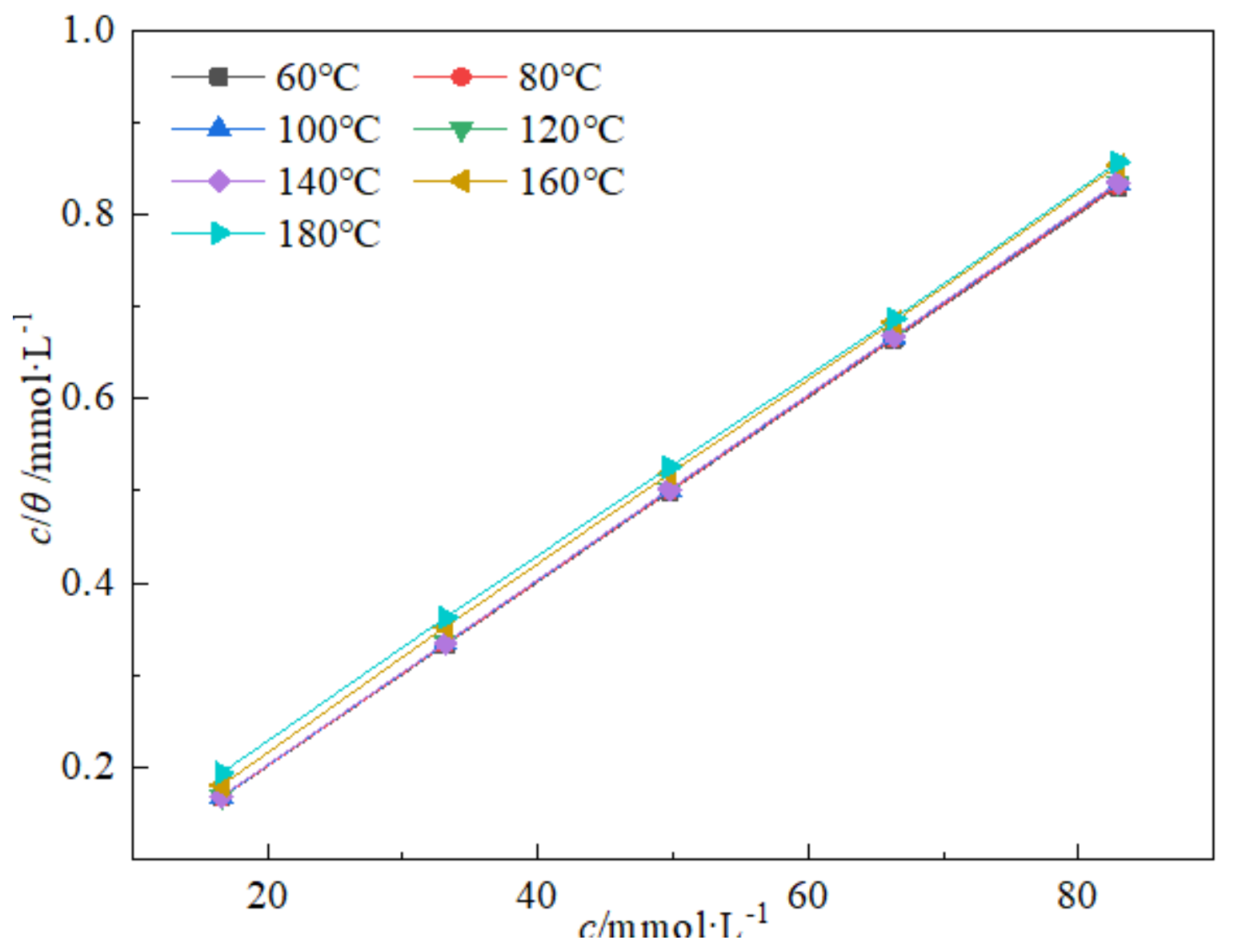

Figure 9

Curves fitting of the corrosion data for steel at different temperatures. 


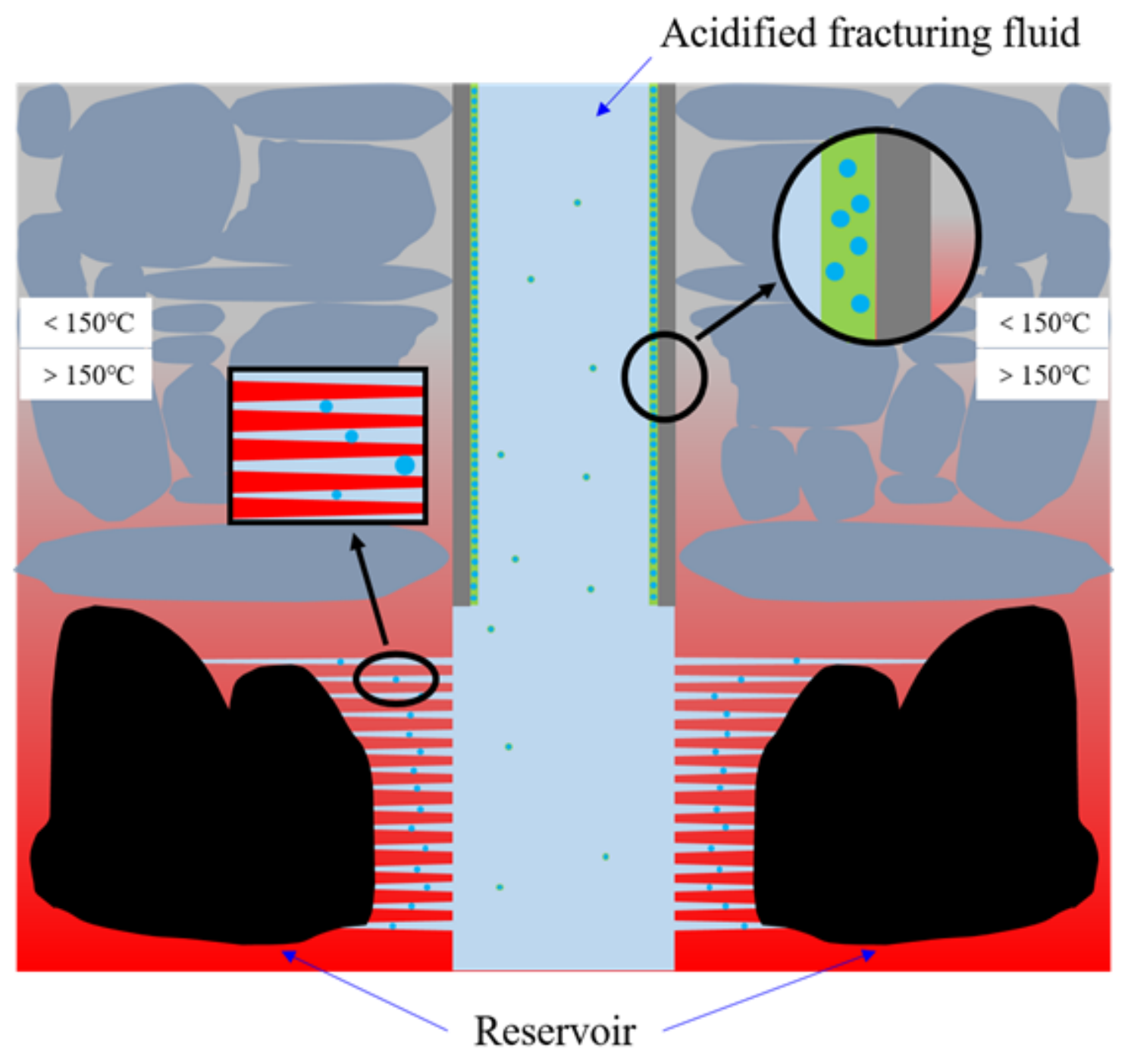

Figure 10

The mechanism of nano-SiO2@OBQA (The color of the formation changes from gray to red, indicating that the temperature of the formation increases with the depth increase.) 